\title{
Transactional Analysis and Multiple Intelligences - A Proposed Diagnosis and Intervention
}

\author{
(C) 2020 Regina Berard
}

This paper appeared originally in Portuguese as Análise transacional e Inteligências Múltiplas - Uma proposta de diagnóstico e intervenção. Revista Brasileira de Análise Transacional , 2011, 1, 161-172 and is reproduced here by kind permission of UNATBRASIL - União Nacional de Analistas Transacionais - Brasil.

Where possible, quotations have been adjusted to reflect original English publications, particularly for TA publications.

\section{Abstract}

The diagnosis of ego states in action is the first step taken by a transactional analyst in order to develop an intervention plan. Multiple Intelligences theory can help with this by enabling recognition of the abilities and competencies that the client has already, and how the Adult ego state may then become decontaminated and energised. The present study discusses the relationships between the concepts of ego states and multiple intelligences and how this can help with facilitating diagnosis and clinical intervention.

\section{Keywords}

ego state, multiple intelligences, contaminated thinking, transactional analysis.

\section{Introduction}

As a Transactional Analyst, I have gained much experience over the years of the existential positions (Berne, 1961, 1972) of clients who come to the clinic. Based on these experiences, I have considered Bernian theory in order to elaborate some ways to understand the processes of how personality is constituted.

The purpose of this paper is to demonstrate a relationship between ego states and the theory of multiple intelligences as described by Gardner (1994), as an aid to diagnosis and clinical intervention planning by psychotherapists. I also want to demonstrate that stimulating specific intelligences and the corresponding abilities allows decontamination and energizing of the Adult ego state to happen in a playful, good-natured and enriching way as it awakens in the client resources, skills and abilities that have not yet been activated or of which the client is not yet aware.

\section{The Theory of Transactional Analysis} TA is a psychological approach created by Eric Berne (1958), a Canadian psychiatrist. Characteristics which define it include a positive philosophy of trust in the human being. Berne says that we are born with the capability to obtain success and satisfaction unless we have a serious organic impediment. This means that we are all born $\mathrm{OK}$ and that education and the environment can produce undesirable effects. TA is a theory that uses simple language and can be understood by an eight-year-old child. The practitioner-client relationship is based on the contract, which is an objective goal of positive behavioural change to be achieved during treatment.

The main concepts that TA uses to understand the human being are: ego states and transactions communication occurs between people from three different ego states; social stimuli or strokes recognition of the existence of the other; time structuring - how we use time in our social relationships; psychological games - conflicts in relationships; emotions - feelings and their expressions; existential position - how I perceive myself in relation to other people; and life script - a life plan developed in early childhood, based on parental influences.

TA focuses on the study of ego states, which we can understand as coherent systems of thought and feelings, manifested by corresponding patterns of behaviour. The term ego state designates states of mind and their behaviour patterns as they occur in nature. Each human has three types of ego states: first, those derived from parental figures, colloquially 
called Parent - in this ego state the person feels, acts, speaks and reacts as one of their parents or other authority figure did when the individual was a small child. The second is the ego state in which the person analyses their environment objectively, calculates possibilities and probabilities based on past experience, and is called the Adult ego state. In the third, each human carries within themselves a little child who feels, thinks, acts, speaks and reacts in a manner similar to how they did when they were a child - relics of our past - and called the Child ego state.

The initial task of a transactional analyst is to identify which ego states are in operation and whether they are operating in a positive or negative circuit. The positive circuit refers to behaviours that a person adopts in their life which leads to well-being and achievement of goals; the negative circuit refers to behaviours that do not generate well-being and instead promote conflicts and non-achievement of goals. This identification process can be performed using diagnostic criteria proposed by Berne, in the following order: behavioural - observation of conduct, gestures, postures and vocabulary; social reaction - the ego states which arise [in others] in response to the person's behaviour and transactions; historical - when the individual identifies how the behaviours were learned in their past; phenomenological - the reliving of experience in the here-and-now.

An important part of diagnosis is identifying which ego states are active at a certain time, and the displacement from one ego state to another. Berne (1961) suggested that the displacements between ego states are due to three factors: "the forces acting within each state; the permeability of the boundaries between ego states and the cathectic capacity of each ego state" (p.41). The concept of cathexis is defined as the psychic energy flowing between the ego states, and therefore the existence of some kind of boundary between ego states is implied. Anomalies in the psychic structure are related to these boundaries and a very common pathology is referred to as contamination.

\section{Contaminated Thinking}

"Thinking is contaminated when the boundaries of the Adult ego state are not strong enough to hold back Parental prejudices and Child delusions. The boundaries are neither lax nor semipermeable. They are overly permeable. (James, 1986, p.192).

Adult ego state can be contaminated by Child, Parent or both ego states at the same time. With contamination, the prejudices and delusions that come from the Parent and/or the Child are experienced by the client as syntonic with the Adult and defended as such.
Berne wrote that cure in TA occurs when clients are able to use their Adult effectively, and that this is possible when the Adult has been decontaminated from parental influences and/or archaic experiences. Moving the psychic energy through the ego state boundaries, and finding new options to face daily challenges, is an invitation for the client to move towards autonomy, the major goal of TA. The TA concept of autonomy was described by Berne as the expression of three capacities: awareness, spontaneity and intimacy. Erskine and Trautmann (1996) emphasise the Integrated Adult, saying that "... the process of integrating the personality, which includes helping clients to become aware of and assimilate the contents of their fragmented and fixated ego states into an integrated neopsychic ego, to develop a sense of self that decreases the need for defense mechanisms and a life script, and to reengage the world and relationships with full contact. It is the process of making whole: taking disowned, unaware, unresolved aspects of the ego and making them part of a cohesive self." (p.316).

Every psychotherapist develops their art, through clinical practice, of decontaminating and energising Adult ego states. This article demonstrates how the theory of multiple intelligences can be integrated with TA for the process of diagnosis and clinical intervention.

\section{The Theory of Multiple Intelligences}

American psychologist Howard Gardner (1983) introduced the theory of multiple intelligences (MI) with a book entitled Structures of the Mind. The great contribution of this theory is to demonstrate that we are intelligent in various ways and that these intelligences can develop according to environmental stimuli. For Gardner, intelligence is biopsychological and this means that the person is able to solve problems, make decisions, be creative, work in teams, generate new problems to be solved or produce products that are important in a particular cultural environment or community.

Some characteristics define the intelligences. The first is the independence between them, even when they are operating together. This means that it is possible to stimulate a less developed intelligence from a more developed intelligence. There is no hierarchy between them and therefore one intelligence is not defined as more important than another. Another important aspect is that intelligence has a biological inheritance but they can still be conditioned by the environment, which means that environmental stimuli can develop or block certain intelligences. Each intelligence has specific skills and competencies. Gardner has delineated eight of them: 
- Linguistic Intelligence denotes a person's ability to organise words into sentences, clarity in expressing and organizing ideas in spoken and written form, and assessing complex meanings. This intelligence is present in poets, orators, sellers and advertisers.

- Logical/mathematical Intelligence refers to a person's ability to calculate, perform complex mathematical operations, and find solutions to logical problems. The person will also be able to relate facts and evaluate consequences, recognise patterns and make deductions. This is present in scientists, mathematicians, accountants, engineers, programmers, architects, accountants and researchers.

- Spatial Intelligence is characterised by a person's ability to spatially represent the world, to have a sense of direction, to recreate images by memory and to move into the past and the future in their mind. Present in engineers, sailors, geographers, navigators, painters, sculptors, drivers and surgeons.

- Bodily/Kinaesthetic Intelligence is the ability to work skilfully with objects, both those involving finger mobility and those that involve full body use, motor coordination, control and body perception, including sensations. It is present in athletes, dancers, surgeons, sculptors and artists.

- Interpersonal Intelligence is revealed in an individual's ability to relate to people, perceive their moods, feelings, beliefs, emotions, motivations. It involves the ability to work cooperatively with people in verbal and nonverbal communication, to recognise social roles and the importance of social environment in the actions of the individual. Present in leaders, politicians, teachers, therapists, parents (educators in general), activists, negotiators, diplomats.

- Intrapersonal Intelligence is the ability to build a refined perception of yourself, recognise your strengths and weaknesses, and feel good about yourself. A person with this well-developed intelligence controls their emotions, manages their feelings and their projects. Present in therapists, spiritual leaders, motivational speakers, philosophers and psychologists.

- Naturalist Intelligence is the ability to observe patterns of nature, identifying and classifying objects and understanding natural systems (such as birds, fish, mammals, plants) and those created by man (such as different types of cars, shoes, toys, clothes). Categorisation is also a fairly strong feature in this intelligence. Present in naturalists, farmers, botanists, hunters, ecolog- ists, biologists, decorators, collectors, navigators and landscapers.

- Musical Intelligence is the individual's ability to think in the form of music, to interpret, write, read and express themselves through music. Musical intelligence clearly perceives tone or melody, rhythm or frequency and grouping of sounds and their intrinsic characteristics, called timbre. Present in musicians, choreographers, music critics, maestros, DJs, tuners of musical instruments, composers, sound engineers, singers.

It is important to note that every human being is capable of developing all their intelligences unless they have brain damage. The intelligences are observable but not measurable. There are several inventories that allow anyone to observe the dynamics of their intelligences and see which are more developed and which need stimulation for their awakening. The environment in which the person finds themself may or may not value particular intelligences and the abilities and competencies derived from such intelligence. In order for someone to develop a certain characteristic or resource, they need to develop the relevant intelligence. For example, to make deductions or relate facts requires the development of logical/mathematical Intelligence.

\section{Common points between theories - TA and MI}

The basic assumptions of each theory are similar, in that they include trust and OKness of humans and that all have the ability (intelligence) to achieve success and satisfaction unless they are brain-damaged or have serious health problems. Stimulating a particular intelligence and its corresponding abilities will allow a person to experiment with new roles and new behaviours, meaning that they will change from one ego state to another and from a negative to a positive circuit.

- In Logical/Mathematical intelligence, we can visualise the Adult in action because of the ability to make logical deductions, plan, relate facts and analyse consequences. Skilful questioning according to Berne the first therapeutic operation [Berne, 1966, and called by him 'interrogation'] by the practitioner allows the client to expose their internal contents, fantasies, secret desires, as well as their way of seeing the world. Knowing what and how to ask is of fundamental importance in creating a trustworthy practitioner-client bond. Questioning allows the practitioner to perceive how readily the client analyses facts and assesses the consequences of their behaviours, and to register what the client does well and how the client has learned to do that. Being a positive experience, the practitioner can anchor the skills 
and resources and thus assist the client in organizing information to use at an appropriate time.

- Spatial Intelligence allows us to walk the timeline, so the client can move back into the past and review the introjections from authority figures. Regressive techniques can be used at this time for the Child to make the necessary decisions and become free of parental programming. In many instances, redecision occurs spontaneously and naturally, when the Adult possesses the appropriated resources and skills and uses them to overcome the problematic situation experienced in the Child. Moving to the future allows the Free Child to use their imagination and creativity to create situations where they are comfortable, and to organise in the here-and-now to achieve their goals. This organisation foresees the use of resources and capabilities to break the commands of the Parent.

- Naturalist Intelligence is characterised by classifying and identifying patterns and the Adult actively participates in this intelligence when it recognises the repetitive and stereotyped patterns that compose the life script.

- The Bodily/Kinaesthetic Intelligence enables the client to perceive subtle sensations that occur in the body, such as a change in breathing, or facial or body movements that may reveal some aspect of the internal dynamics that has hitherto been discounted. It is possible to become conscious of some repressed feeling in the Child and to receive permission from the practitioner to express that feeling freely.

- Interpersonal Intelligence, in addition to inviting Free Child to express itself and seek new, healthier relationships, also encourages the Adult to find appropriate form and language (transactions) to maintain relationship.

- Musical Intelligence stimulates art and aesthetics as a way to find quality-of-life and well-being, putting the Child into a state of relaxation and fun.

- Intrapersonal Intelligence is the perception of self, of the qualities and weaknesses that we possess, the awareness of our desires and purposes. In developing this intelligence, the Free Child regains spontaneity and creativity to express desires.

- Linguistic Intelligence permeates all other intelligences during the therapeutic process, stimulating Adult to organise thinking and communication of ideas effectively, including organising words into sentences clearly and expressively.
Following TA diagnostic criteria, the practitioner will survey which ego states are in evidence and how they are contaminating the Adult. This diagnosis is made for clients so the practitioner can undertake intervention planning. Along with this assessment, it is possible to identify which intelligences are available and which are dormant, since the abilities and competencies of each intelligence are perceptible in the client's report, the way in which the information is organised, and what they believe is the reason for their problems. With the observations already made, it has been found that logical/mathematical and spatial intelligences contribute significantly to the processes of decontamination and energization of the Adult. Welldeveloped logical/mathematical intelligence allows the client to deal with different ideas or subjects and check them against reality, mainly in their emotional aspects, besides allowing them to evaluate the consequences of certain behaviour. When this intelligence is underdeveloped, it is advisable to activate it as soon as possible because otherwise the person will have difficulty in connecting their thoughts and feelings with the corresponding elements in their environment. Ways to activate this intelligence include asking the client to recognise the learning gained from a previous experience, and thinking of different transactions or behaviours to respond to a particular stimulus.

With spatial intelligence developed, the practitioner can encourage the client to take into the past the resources needed to change a negative experience, as well as to take that into the future. Optimising the resources in this way energises the Free Child. Imagining new behaviours, experiencing new sensations, and detaching from old patterns of behaviour, allowing the client to strengthen the boundaries of the Adult.

These two intelligences give psychological support to the client to organise emotional content and to visualise with more clarity the changes to be made in their life. From there, depending on the contract between the client and practitioner, the other intelligences can be investigated with a view to meeting the contract. When a client approaches a practitioner, generally their intrapersonal intelligence needs to be strengthened and expanded, and this is the end result that needs to be achieved.

The following case study demonstrates the therapeutic process, focusing on the intelligences and the ego states.

A psychiatrist had referred a 40-year-old single woman with severe depression that was having damaging consequences within her work environment. She was a teller at a large bank and at least twice a week there were financial discrepancies in her till, with the shortfalls being deducted from her salary. Additionally, 
the woman did not take pleasure in doing anything different on weekends, spending time cleaning house and taking care of her relatives. She had become involved with a married man, who was gradually moving away from her and this was leading her to a state of great anguish. Another concerning factor was intense hair loss which was not responding to treatment.

At the beginning the woman spoke very little, expressing the will to die. When the intelligences were considered, it became evident that her spatial intelligence was completely missing; when she was asked to close her eyes and imagine a situation in the past and the future, she could not see it. Nothing happened when she was asked to look at an object in the room and then close her eyes and visualise it mentally.

It was also evident that her day-to-day life was constrained with obligations and responsibilities, with little room for any fun or caring for herself. Logical/mathematical intelligence was not being used to evaluate the effects of her actions on her state of health.

The focus of the therapy was to develop spatial intelligence abilities in order to cathect Free Child, as well as strengthening Adult to be able to evaluate and manage day-to-day events. Several exercises were given for this purpose. The client was asked to look at objects for some time and then close her eyes and visualise them. At another time the exercise was to observe objects or people and then to draw or paint them. During therapy the woman liked to talk in detail about everything that had happened during the week and also to comment on the effects of the exercises. Over time, her Child emerged and the therapeutic bond strengthened. At the end of each session, she began to ask for new exercises, saying that she liked to do them. After three months of treatment, the client reported with some enthusiasm that she now had the ability to mentally visualise observed objects. She also reported that the financial losses at work had declined.

After approximately six months of treatment, the client revealed a secret desire to paint on canvases, which she had never carried out because she considered it impossible. Over the course of a year of work, exercises had been conducted at increasing levels of complexity - for example, mentally creating a blank screen and projecting past situations or future creations onto this screen. At this time, the association of spatial intelligence with bodily/kinaesthetic intelligence was made by relating the images to the sensations or emotions that those images aroused. During this period the patient began to report new behaviours and attitudes in her daily life, including a considerable reduction in taking care of the well-being of others, and greater attention to her own needs. She started meeting with friends and planning activities on weekends, applying logical/mathematical intelligence skill. At the end of the first year, she took her desire to paint more seriously and began looking for a teacher for this activity. She felt strong and secure enough to terminate the bond with the partner, as she found new ways to be accepted and taken care of.

By the end of the second year of treatment, she was already painting pictures with a hitherto unknown spatial intelligence ability, her Free Child had enough space to express her desires, and her Adult began to take care of such desires and plan how to fulfil them. By now the symptoms of depression and hair loss were gone, the money in her till was now balancing, and her memory and mindfulness were present. She felt strong, alive and able to move on with her life, and decided that her therapy was complete.

Throughout the therapeutic process, spatial intelligence was the focus of attention and was gradually associated with bodily/kinaesthetic intelligence. In this way, the Free Child gained space in her life. Whenever she attended a session, she received support and encouragement from the practitioner to express herself. The strengthening of her Adult to plan and take care of her needs allowed the release of much energy that was used by Child. The logical/mathematical intelligence skills had been broadened and directed towards intrapersonal intelligence (good self-perception).

\section{Final Considerations}

The decontamination and energising of the Adult, taking into account the abilities and skills of the various intelligences, encourage clients to continue in the process of self-knowledge, as well as elevating selfesteem, so they feel more and more capable of being autonomous. Recognising that we are all intelligent in some ways fosters a trusted therapeutic contact, as does conviction in the client's ability to find ways to rethink the decisions made in childhood about themselves, others and the world. Clients feel valued and respected in their life trajectory, and discover with a certain humour that they can experience themselves in different roles, feel new sensations, and plan the future with more freedom.

The content of this article is drawn from my clinical practice and discussions with study colleagues over many years of experience. I do not claim to establish any unquestionable truth. It is a proposal to consider and an invitation to have a 'new look' at the person in front of you.

Regina Berard is a Teaching member in training of UNAT-Brasil and a Master Practitioner of NLP. She can be contacted on reginaberard@gmail.com 


\section{References}

Berne, E. (1966). Principles of Group Treatment. New York: Oxford University Press.

Berne, E. (1961). Transactional Analysis in Psychotherapy. New York: Grove Press.

Berne, E. (1972). What Do You Say After You Say Hello? New York: Grove Press.

Berne, E. (1958). Transactional analysis: A new and effective method of group therapy. In P. McCormick (Ed.), Intuition and ego states: The origins of transactional analysis. San Francisco: Harper and Row.
Erskine, R., \& Trautmann, R. (1996). Methods of an Integrative Psychotherapy Transactional Analysis Journal, 26(4), 316-328.

https://doi.org/10.1177/036215379602600410

Gardner, H. (1983). Multiple Intelligences: The Theory in Practice. New York: Basic-Books.

James, M. (1986). Diagnosis and Treatment of Ego State Boundary Problems Transactional. Analysis Journal, 16(3), 188-196. https://doi.org/10.1177/036215378601600308 